\title{
Role of Secondary Stage Teachers in West Bank Schools in Raising the Students' Awareness of the Intellectual Extremism from Students Point of View
}

\author{
Yousef Samara, PhD student in the department of educational leadership and foundations. University of Jordan \\ Professor Mohammed Salim Al-Zboun. University of Jordan, Faculty of Education Sciences \\ Dr. Amani Faisal Qashmer. University of Jordan
}

\begin{abstract}
This study aims at recognizing the role of the teachers of the secondary stage of education in the schools' of the West Bank in raising the awareness of students about the phenomenon of intellectual extremism from the point of view of students. The study population comprises the students of the governmental schools in the Northern region of the West Bank in the academic year (2019-2020). The representative sample of the study consists of (382) female and male students from the governmental schools in the West Bank (the northern region of the West Bank). The researchers used the questionnaires as the study tool by adopting the descriptive analytical methodology. The results of the shows that the degree of the role of the secondary schools' teachers in the West Bank in raising the awareness of students about intellectual extremism from the point of view of students is "medium". In addition, it is clear that there are statistical differences in the role of the secondary school's teachers in the West Bank in raising the awareness of students about intellectual extremism according to the variable of gender that it came in favor of males. In addition, there are not statistical differences according to the variable of major and qualifications. In light the previously mentioned results, the researcher recommends to put a strategy adopted by the Ministry of Education in order to raise the awareness about intellectual extremism in students by developing their sense of responsibility towards their society. In addition, it is recommended that it is imperative to develop the curriculum and teaching methods by focusing on the religious aspect of the society.
\end{abstract}

Keywords: Intellectual Extremism, West Bank, Student Awareness.

DOI: $10.7176 / \mathrm{JEP} / 10-36-03$

Publication date: December 31st 2019

\subsection{Introduction}

The age that accompanies our lives today is witnessing rapid change and amazing progress in various fields of education, social, political, economic and cultural. In doing so, societies must continuously reform education systems in general to meet a range of challenges in order to prepare the individual so that they have ideas and principles that are based in their entirety with the religious and societal frameworks. It is clear from the openness of the Arab world due to the tremendous developments in the field of media and the progress in the use of social media networks, and their impact on individuals and society, that they have profound effects on their behavior and ideas, and these developments have allowed individuals to access information without restrictions, and forming a special world that is full with the ideas that they want, and then reinterpret according to their own directions without the presence of a direct censor (Laroche, Habibi, Richard \& Sankaranarayanan, 2012).

With the penetration of many ideologies on these channels, it became easy to reshape the human mind with behavioral ideas and patterns that deviate from the beliefs of peoples and their value, intellectual and religious premises, and turn their ideas and behavior towards extremism and exaggeration, and compel them to embrace trends, tendencies and beliefs that do not conform to the intellectual system of society. Hence the importance of universities in re-making the human aware mind, which is belonging to its religious and value beliefs, in addition to developing their ability to select ideas that are characterized by moderation, and which proceed according to the societal and religious frameworks (Hayek, 2018).

The ideal goal of education is to develop the individual and prepare him for integration into society according to the political, social and intellectual system of the society, as education is the process that changes all systems related to humanity, and from all aspects of life. Education is one of the most important elements that takes change into consideration in the same context, and therefore education is not a static process but rather a dynamic process in its goals, content and outputs, and it is also concerned with providing individuals with an optimal way to overcome the difficulties of life and get out of all crises, especially intellectual crises. This is because education maintains the formation of the mind in its framework that derives from its religious, societal and values, and sets out towards selecting ideas and their justifications so that they do not go out of that framework and lead in their entirety to intellectual stability, which is reflected in the stability of the individual on the one hand and society on the other hand (Ali, 2007).

Educational thought includes positive connotations that are reflected in the formation and fulfillment of society's desires. On the other hand, extremist thought is a reason for the decline of the basic elements that constitute the 
ideas and principles of peoples. Doctrinal and intellectual formation that forms the general framework of society, so educators must search for how they can stop this deterioration that leads the individual and society towards extremism and deviation, especially as the educational role is seen as the setting that enables society Growth and stability (Al-Agha, 2010).

The phenomenon of extremism is considered one of the phenomena that arouse controversy and concern on the part of all members of society with their different names. Therefore, the growth of this phenomenon and its transmission to advanced stages did not exist by families, who must be reconsidered in a deeper manner and thus far from simplification, which may prejudice careful analysis. For this phenomenon, we re-realize it with its overall dimensions and form a true picture of the reasons that lead to the formation of this phenomenon and its growth within societies (Muhammad, 2015).

Extremism is one of the main issues that many contemporary societies care about, as it is a daily life issue, which extends its borders in the structural formation of ideas, ideals and ideology that society accepts, and extremism has many types of it, religious extremism, political extremism, social extremism, and intellectual extremism, which is the most dangerous for the individual and society alike (Jose, 2008).

Intellectual extremism is defined as the exaggeration of intellectual or behavioral militancy through a set of religious, ideological, political or economic ideas, as the individual reaches the belief that he possesses the whole truth, and these ideas are due to the increasing gap between the individual and the social fabric to which he belongs or is present, Which leads him to feel alienated from himself and from the community around him (ElBorai, 2002).

The causes of intellectual extremism are due to the entry of a group of deviant religious concepts that are limited to dogmatic fanaticism and religious extremism, in addition to the intellectual void of youth and militancy in religion with the absence of a value system and economic and social factors, and the absence of places designated to absorb the energies of youth, in addition to the weakness of the educational institution and accreditation On methods of repression, threats, and lack of social justice (Al-Youssef, 2006).

Intellectual extremism has negative repercussions on the political, intellectual, social, economic and developmental system, and despite the efforts being made at the local, Arab and Islamic levels to address intellectual deviation, its spread is increasing, and one of the most important reasons for the failure of Islamic societies in this regard is to ignore the role of education that constitutes the difficult equation in overcoming the problem that afflicts these societies (Al-Rawashdeh, 2015).

\subsection{Problem statement}

The family is no longer the only element that constitutes the personality of the individual and works on its development in all aspects, whether psychological or intellectual, but schools have a great role in deepening the thinking of students in selecting ideas within the framework and general beliefs, whether religious or community, and thus schools have a large and prominent role in the process of building and formulating ideas for students so that they have the ability to choose their ideas that are characterized by mediation and moderation, away from exaggeration and extremism, so as to ensure stability and positive interaction for students after they graduate from them and joining universities and their involvement in the social framework, and this what identifies the problem of this study in its attempt to answer the following questions:

- What is the role of secondary school teachers in West Bank schools by educating students about the phenomenon of intellectual extremism from the viewpoint of the students themselves?

- Are there statistically significant differences at $(\alpha=0.50)$ in the estimates of the study sample towards the role of secondary school teachers in West Bank schools by educating students about the phenomenon of intellectual extremism according to gender, level of parent education and specialization variables?

\subsection{Purpose of the study}

The study aims to explore the role of secondary school teachers in West Bank schools is known to educate students about the phenomenon of intellectual extremism from the viewpoint of the students themselves and the relationship of this to some variables.

\subsection{Importance of study}

The importance of the study is that it deals with the role of secondary school teachers in West Bank schools by educating students about the phenomenon of intellectual extremism from the viewpoint of students themselves, and highlighting the prominent role of the educational system in educating students about the phenomenon of intellectual extremism in light of the emergence of many developments and events that afflict Islamic Arab societies in the Arab world, and the emergence of many extremist groups, and the exploitation of openness and the Internet that spread ideas that lead to fanaticism and extremism of all kinds.

The importance of the study also stems out of the importance of the educational system in educating students about the phenomenon of intellectual extremism in light of the developments and events experienced by the Arab world in general and the Palestinian community in particular, and these events are illegal openness and the entry of many false beliefs that conflict with religion, custom and traditions and the reflection of these events on 
Thinking and minds of individuals and controlling their thoughts and minds.

The importance of the study also comes out of that there is a dearth of published studies and research in this field that dealt with the role of educational systems to raise awareness of the phenomenon of intellectual extremism, as research has recently focused on the implications and effects of the phenomenon of extremism on the individual and society without having research aimed at educating students about the phenomenon of extremism from the point of view researchers.

\subsection{Terminology}

The educational role: It is defined procedurally as a set of means, methods, procedures and practices that the educational system undertakes to educate students in all fields. It will be measured by answers of the study sample on the tool prepared for this purpose (Kiraly, 2014).

The educational system: A set of principles, strategies, concepts, and scientific information that are arranged and coordinated to suit all stages of life, and are included within books, so that the student can reach, and so that the information can be communicated to him through a specialized trainer with teaching methods under administrative and educational supervision (Al-Huni, 2013).

Intellectual extremism: "Taking an individual's stance is characterized by strictness and deviation from the level of moderation and distance from the norm and exceeding intellectual norms and moral values that have been defined and accepted by members of society. It means the individual's responses that are distant from moderation in political, religious and social situations, because he either accepts the thing absolutely, or rejects it rejecting absolutely regardless of the content or reasonableness of the thing. It is a seedbed and an intellectual base for all forms of intolerance, racism, exclusion of the other, and any translation of destructive behaviors that may follow it (UNESCO, 2016).

\subsection{Study limitations}

The study is determined by the following limitations:

Objective limitations: The study examines the role of secondary school teachers in West Bank schools by educating students about the phenomenon of intellectual extremism from the viewpoint of the students themselves.

Time limitations: The study was implemented in the academic year 2019/2020.

Geographic limitations: This study was limited to the areas of the northern West Bank.

Human limitations: The study was limited to a sample of high school students in Palestinian schools for the academic year 2019/2020 in the northern West Bank.

\subsection{Previous studies}

Al-Agha (2010) conducted a study aimed at identifying the phenomenon of extremism in the Palestinian society in Gaza Governorate, and to know the most common reasons that pushed for the acceleration of extremist behavior, and then set an educational vision to confront extremism and get out of this impasse. The researcher used the descriptive method, and a simple random sample of educators was used, and the number of its members reached (158) individuals, and the study reached many results, including: The intellectual extremism in the Palestinian society in Gaza governorates is very high, where the degree of the reality of extremism got a relative weight of $(69.56 \%)$. The most common factors fueling extremism were social factors, which ranked first with a relative weight of $(83.7 \%)$, and political parties, which received a relative weight of $(80.99 \%)$, and then an educational vision was set out of the crisis of extremism.

Simi (2015) conducted a study aimed at researching various factors related to childhood trauma and adolescent behavioral problems and their relationship to the process of entering violent extremism, and the sample of the study consisted of (44) former members of violent groups in the United States, and the results showed that psychological trauma in childhood may be the beginning For dangerous behaviors that lead to extremism, as some cases have shown inconsistent behavior such as self-mutilation or suicide as evidence of psychological problems.

Cannatella (2012) conducted a study aimed at identifying the role of ideas of African American students toward violence and extremism, and the researcher used the descriptive survey method, and through a sample of (116) students from the University of Southern Louisiana, including (62) males, and (54) Of the females, and to achieve the goals of the study, a questionnaire was developed. After distributing, collecting and analyzing it, the study concluded that there are differences among males in the role of special ideas towards violence.

Al-Tayyar (2017) conducted a study aimed at identifying the manifestations of intellectual extremism among high school students. The study relied on the descriptive approach through relying on the questionnaire as a tool to collect data. The questionnaire was distributed randomly and irregularly, the total number of the study sample after the distribution of questionnaires to A sample of (384) individuals. The study found that one of the most important manifestations of intellectual extremism: a tendency to isolationism, and dealing with other students with a kind of mistake, and with regard to factors affecting the role of high school in enhancing security awareness to prevent intellectual extremism, the results of the study indicated that the presence of statistically significant differences between the point of view of the sample members towards its axes with a variable (school 
type, age, and variable number of years of experience). With regard to the variable of the academic qualification, the results of the study showed that there were no statistically significant differences in the averages of the study sample towards the proposed methods to activate the school's role in enhancing Security awareness to protect students from intellectual extremism according to the variant of the type of educational qualification.

Qasim and Ibrahim (2017) conducted a study aimed at defining the phenomenon of intellectual extremism and knowing its causes and manifestations, and the role of the teacher in addressing this phenomenon, as confronting the phenomenon of intellectual extremism is necessary for the safety of conditions at the family, school and community levels, thus maintaining security, unity and cohesion of the state Where the study was based on the descriptive approach, and in order to achieve the objectives of the study, the researchers designed an open questionnaire as a tool for the study, a random sample consisting of (144) teachers was selected, and after analyzing the data, a set of results was reached, the most important of which was the presence of many effects of extremism, where it indicates The teachers have the first effects The consequences of intellectual extremism are Islamic disintegration and lack of social communication, and it turns out that one of the most important ways to prevent intellectual extremism is the correct understanding of Islam, attention to family education, and awareness using the media, as it was found that there are many roles for teachers to treat the phenomenon of intellectual extremism, the most important of which was the discussion of students In these ideas and their destructive effects.

Al-Tamimi and Ramadan (2018) conducted a study aimed at identifying the degree of school principals practicing intellectual security to confront the phenomenon of extremism in the middle stage from the point of view of the managers themselves. The research sample consisted of 45 principals and managers, with $78 \%$ of the original research community in the Rifai Education Department of the Directorate The education of Dhi Qar Governorate, they were chosen in the inventory method, and due to the nature of the research, the researchers adopted the descriptive approach, and to achieve the goals of the research, a questionnaire consisting of 29 paragraphs was prepared. The results showed that the degree of school principals practicing intellectual security to confront the phenomenon of extremism in the middle stage from the point of view of the managers themselves came with great degree for all areas of the research tool, and that the degree of school administrators exercising intellectual security to confront the phenomenon of extremism in the middle stage from the point of view of the principals themselves with different sex came in favor of males.

\subsection{Methods and procedures}

In order to achieve the aims of the study, the survey method was used because it is best suited for this type of study. Consequently, the study relied on the methodology of descriptive analytical statistics.

\subsubsection{Study population and sample}

The study population consisted of all secondary school students in the northern West Bank, and they were chosen clustery. The number of students was 56,583 male and female students, while the study sample was randomly chosen based on the statistical tables, and the study sample reached (383) male and female students, and a description of the characteristics of the study sample according to its variables is illustrated in table (1).

Table (1): Distribution of the study sample according to its variables

\begin{tabular}{|l|l|c|c|}
\hline \multicolumn{1}{|c|}{ Variables } & \multicolumn{1}{|c|}{ variable categories } & Frequency & Percentage \\
\hline \multirow{4}{*}{ Gender } & Male & 181 & $47.4 \%$ \\
\cline { 2 - 4 } & Female & 201 & $52.6 \%$ \\
\cline { 2 - 4 } & Total & 382 & $100 \%$ \\
\hline \multirow{3}{*}{$\begin{array}{l}\text { Specialization } \\
\text { The educational qualification }\end{array}$} & Scientific & 110 & $28.8 \%$ \\
\cline { 2 - 4 } & Humanitarian & 272 & $71.2 \%$ \\
\cline { 2 - 4 } & Total & 382 & $100 \%$ \\
\cline { 2 - 4 } & Less than high school & 141 & $36.9 \%$ \\
\cline { 2 - 4 } & University & 64 & $16.8 \%$ \\
\cline { 2 - 4 } & Total & 177 & $46.3 \%$ \\
\hline
\end{tabular}

\subsubsection{The study tool}

The researchers prepared the study tool (the questionnaire) after reviewing the study literature and previous studies related to the subject. The questionnaire included two sections, the first section was the demographic data, and the second section included data for the study variables, as the number of the tool items reached (36) items, and was designed on the basis of a five-dimensional Likert Scale, and the paragraphs were built in a positive direction.

\subsubsection{Validity of the study tool}


The validity of the tool was verified by presenting it to a group of arbitrators with expertise and experience in the field of educational sciences in the Palestinian universities and asked them to express an opinion on the questionnaire paragraphs by deleting and amending and proposing new paragraphs, and if the tool is suitable for the subject of the study, and based on the arbitrators' notes the study tool was modified with its final form, it consists of (36) paragraphs.

\subsubsection{The study tool reliability}

The reliability coefficient was extracted using the Alpha Cronbach equation, where the coefficient of reliability was (0.92). These values for the reliability coefficients were appropriate and fulfilled for the purpose of the study.

\subsection{Results and discussion}

Results related to the first study question: What is the role of secondary school teachers in West Bank schools by educating students about the phenomenon of intellectual extremism from the viewpoint of the students themselves?

In order to answer this question, the arithmetic means and the standard deviation for each item of the study tool were extracted, and table (2) shows that.

Table (2): Arithmetic means and standard deviations of the role of secondary school teachers in West Bank schools by educating students about the phenomenon of intellectual extremism from the viewpoint of the students themselves

\begin{tabular}{|c|c|c|c|c|c|}
\hline No & Paragraph & $\begin{array}{l}\text { Arithmetic } \\
\text { means }\end{array}$ & $\begin{array}{c}\text { Standard } \\
\text { deviations }\end{array}$ & Rank & Degree \\
\hline 1 & $\begin{array}{l}\text { The teacher practices self-actualization and self- } \\
\text { confidence skills. }\end{array}$ & 3.86 & 0.66 & 1 & High \\
\hline 2 & $\begin{array}{l}\text { The teacher contributes to helping the learner } \\
\text { overcome obstacles. }\end{array}$ & 3.66 & 0.64 & 2 & High \\
\hline 3 & $\begin{array}{l}\text { The teacher takes into account the emotional } \\
\text { aspects of the learner. }\end{array}$ & 3.58 & 0.78 & 3 & High \\
\hline 4 & $\begin{array}{l}\text { The teacher works to provide an example to lead } \\
\text { by students. }\end{array}$ & 3.49 & 0.71 & 4 & Medium \\
\hline 5 & $\begin{array}{l}\text { The teacher contributes to enhancing the positive } \\
\text { responses of students. }\end{array}$ & 3.47 & 0.95 & 5 & Medium \\
\hline 6 & $\begin{array}{l}\text { The teacher submits the scientific material } \\
\text { properly. }\end{array}$ & 3.47 & 1.12 & 5 & Medium \\
\hline 7 & $\begin{array}{l}\text { The teacher practices constructive (forgiveness, } \\
\text { and criticism) values. }\end{array}$ & 3.46 & 0.94 & 7 & Medium \\
\hline 8 & $\begin{array}{l}\text { The teacher works to define educational goals } \\
\text { related to reality. }\end{array}$ & 3.40 & 0.89 & 8 & Medium \\
\hline 9 & $\begin{array}{l}\text { The teacher works to understand the cultural } \\
\text { changes experienced by students. }\end{array}$ & 3.39 & 0.87 & 9 & Medium \\
\hline 10 & The teacher links educational content to reality. & 3.37 & 0.91 & 10 & Medium \\
\hline 11 & $\begin{array}{l}\text { The teacher works on taking into account the } \\
\text { national aspects of the country. }\end{array}$ & 3.33 & 0.88 & 11 & Medium \\
\hline 12 & $\begin{array}{l}\text { The teacher works to prepare students with the } \\
\text { appropriate intellectual contents. }\end{array}$ & 3.31 & 0.78 & 12 & Medium \\
\hline 13 & $\begin{array}{l}\text { The teacher contributes to helping the learner } \\
\text { overcome obstacles. }\end{array}$ & 3.31 & 0.81 & 12 & Medium \\
\hline 14 & The teacher uses one method of evaluation. & 3.30 & 0.80 & 14 & Medium \\
\hline 15 & $\begin{array}{l}\text { The teacher practices self-actualization and self- } \\
\text { confidence skills. }\end{array}$ & 3.30 & 0.84 & 14 & Medium \\
\hline 16 & $\begin{array}{l}\text { The teacher uses student supportive and interesting } \\
\text { methods. }\end{array}$ & 3.29 & 0.82 & 16 & Medium \\
\hline 17 & The teacher uses one method of evaluation. & 3.29 & 0.79 & 16 & Medium \\
\hline 18 & $\begin{array}{l}\text { The teacher provides appropriate (emotional and } \\
\text { cognitive) content. }\end{array}$ & 3.28 & 0.84 & 18 & Medium \\
\hline 19 & $\begin{array}{l}\text { The teacher submits the scientific material } \\
\text { properly. }\end{array}$ & 3.28 & 0.82 & 18 & Medium \\
\hline 20 & $\begin{array}{l}\text { Educational policies take into account the national } \\
\text { aspects of the country. }\end{array}$ & 3.28 & 0.78 & 18 & Medium \\
\hline 21 & The teacher focuses on (principles, values and & 3.28 & 0.82 & 18 & Medium \\
\hline
\end{tabular}




\begin{tabular}{|c|c|c|c|c|c|}
\hline & ethics). & & & & \\
\hline 22 & $\begin{array}{l}\text { The teacher provides content related to religious } \\
\text { and national values. }\end{array}$ & 3.27 & 1.12 & 22 & Medium \\
\hline 23 & $\begin{array}{l}\text { The teacher works to prepare students with the } \\
\text { appropriate intellectual contents. }\end{array}$ & 3.26 & 0.83 & 23 & Medium \\
\hline 24 & $\begin{array}{l}\text { The teacher focuses on (principles, values and } \\
\text { ethics). }\end{array}$ & 3.25 & 0.81 & 24 & Medium \\
\hline 25 & $\begin{array}{l}\text { The teacher provides content related to religious } \\
\text { and national values. }\end{array}$ & 3.25 & 0.71 & 24 & Medium \\
\hline 26 & $\begin{array}{l}\text { The teacher works to provide sound emotional } \\
\text { qualities. }\end{array}$ & 3.25 & 0.79 & 24 & Medium \\
\hline 27 & $\begin{array}{l}\text { The teacher practices constructive (forgiveness } \\
\text { and criticism) values. }\end{array}$ & 3.25 & 0.77 & 24 & Medium \\
\hline 28 & $\begin{array}{l}\text { The teacher takes into account the emotional } \\
\text { (emotional) aspects of the learner. }\end{array}$ & 3.24 & 0.76 & 28 & Medium \\
\hline 29 & $\begin{array}{l}\text { The teacher provides appropriate (emotional and } \\
\text { cognitive) content. }\end{array}$ & 3.23 & 0.74 & 29 & Medium \\
\hline 30 & The teacher links educational content to reality. & 3.22 & 0.70 & 30 & Medium \\
\hline 31 & $\begin{array}{l}\text { The teacher works to define educational goals } \\
\text { related to reality. }\end{array}$ & 3.19 & 0.69 & 31 & Medium \\
\hline 32 & $\begin{array}{l}\text { The teacher works on the use of intellectual } \\
\text { implications that avoid intolerance. }\end{array}$ & 3.19 & 0.72 & 31 & Medium \\
\hline 33 & $\begin{array}{l}\text { The teacher contributes to using methods related to } \\
\text { the community value framework. }\end{array}$ & 3.18 & 0.70 & 33 & Medium \\
\hline 34 & $\begin{array}{l}\text { The teacher works to provide an example to lead } \\
\text { by students. }\end{array}$ & 3.18 & 0.71 & 33 & Medium \\
\hline 35 & $\begin{array}{l}\text { The teacher is working on the use of intellectual } \\
\text { contents that are far from party ideologies. }\end{array}$ & 3.17 & 0.69 & 35 & Medium \\
\hline 36 & $\begin{array}{l}\text { The teacher uses methods related to the religious } \\
\text { framework of society. }\end{array}$ & 3.11 & 0.57 & 36 & Medium \\
\hline \multicolumn{2}{|r|}{ Total } & 3.32 & 0.42 & & Medium \\
\hline
\end{tabular}

It is clear from the data in the previous table that the role of the secondary school teachers in West Bank schools by educating students about the phenomenon of intellectual extremism from the point of view of the students themselves was between high and medium, and the arithmetic means ranged between (3.86) to (3.11). With regard to the overall degree of the role of secondary school teachers in West Bank schools by educating students about the phenomenon of intellectual extremism from the viewpoint of the students themselves, it was medium, in terms of the arithmetic mean it was (3.32).

This result could be attributed to the awareness of the study sample of the harms of intellectual extremism, as educational institutions are the fertile place that develops awareness of the phenomenon of intellectual extremism, due to the awareness and correct culture it offers students about the negative aspects of the spread of the phenomenon of intellectual extremism on the individual and society, so attention is directed to the teacher as responsible for preparing and educating students about the phenomenon of intellectual extremism, as well as its responsibility in developing their intellectual capabilities to confront the strange beliefs that constitute the seed of the development of this phenomenon in the hearts of students in addition to the role of the teacher in guiding students and immunizing them from deviant and stray ideas in all stages of education, it is Bam The constant controlling authority guides his behavior, controls his behavior and creates positive trends that reject extremism of all kinds, given that students are the covenant and wealth of society.

This may also be attributed to students' awareness and awareness of the role that the teacher can play in order to deepen behavioral ideas and trends that are characterized by moderation and mediation, and the development of these concepts and ideas among students by drawing features of the student's personality, shaping his habits, trends and ideas, developing the student's inclinations and preparations and determining the path of his growth Balanced psychosocial and finding a broad, educated and conscious social base in which the manifestations of good behavior are consistent with the customs, customs and beliefs of society, and contribute to modifying ideas and attitudes and increasing the ability of education to change unwanted ideas and habits, and change Patterns of thinking and diversification among students in a way that establishes their connection with their authentic cultural roots and national religious affiliation, and training students in practical practices and behaviors that stem from ideas that are not overly extreme and extremist, making it a good person involved in building his 
society.

Where the highest ranked paragraph, which states "The teacher exercises (skills of self-realization and building self-confidence) with an arithmetic mean of (3.86). The researchers may attribute this result to teachers keenness to adhere to educational practices and methods that increase students awareness and develop their intellectual capabilities in selecting and analyzing ideas that express themselves and their independent personalities within the frame of reference of society.

The second rank came in the paragraph, "The teacher contributes to helping the learner to overcome obstacles" with the mean of (3.66), and the researchers may attribute this to the sincerity of the affiliation by teachers for their profession, and their awareness of the importance of the youth stage and the necessity of having abilities that exceed all difficulties.

And the third rank of the paragraph states, "The teacher takes into account the (emotional) aspects of the learner." With the mean of (3.58), the researchers may attribute this to teachers' knowledge of the developmental stages of learners, and the necessity and importance of taking into account the emotional aspects at this stage.

The paragraph (The teacher contributes to the use of methods related to the religious framework of society) is ranked as the last paragraph (36) with the mean of (3.11). The researchers may attribute this to the supremacy of the secular style in the country, the teacher's focus on the subject matter of specialization and the lack of linking the educational material to the values and teachings of religion.

Results related to the second study question: Are there statistically significant differences at $(\alpha=0.50)$ in the estimates of the study sample towards the role of secondary school teachers in West Bank schools by educating students about the phenomenon of intellectual extremism according to gender, level of parent education and specialization variables?

Gender: In order to answer this question, the ( $\mathrm{T}$ test) was used for the independent samples and the results are in the table (3) below.

Table (3): The results of the (T) test for the two independent samples to identify the role of secondary school teachers in West Bank schools by educating students about the phenomenon of intellectual extremism from the viewpoint of the students themselves according to the gender variable

\begin{tabular}{|c|l|c|c|c|c|c|}
\hline \multicolumn{2}{|c|}{ Variable } & Frequency & $\begin{array}{c}\text { Arithmetic } \\
\text { mean }\end{array}$ & $\begin{array}{c}\text { Standard } \\
\text { deviation }\end{array}$ & T value & Significance \\
\hline \multirow{3}{*}{ Gender } & Male & 181 & 3.3708 & 0.41023 & 2.069 & 0.03 \\
\cline { 2 - 7 } & Female & 201 & 3.2804 & .440210 & & \\
\hline
\end{tabular}

We note from the data in the previous table that there are statistically significant differences at the level of significance $(\alpha=0.05)$ in the role of secondary school teachers in West Bank schools by educating students about the phenomenon of intellectual extremism from the viewpoint of students themselves according to the gender variable. The value of the significance level reached (0.03) and this value is less than $(0.05)$. This result means that there are differences between students according to their gender in the averages of their responses to the role of secondary school teachers in West Bank schools by educating students about the phenomenon of intellectual extremism, as it was found that the differences are in favor of males and that In terms of the mean, the mean for males is higher than for females. This may be attributed to the fact that males are more involved in being attracted to any strange behaviors or ideas as a result of the varying freedom between males and females, which makes extremist practices outside the female circle, this may be attributed to the fact that the conservative patriarchal system is more strict in its dealings with females, which makes the female It avoids any ideas that lead to extremism, and this may also be due to the nature of the male's training structure in terms of inclinations, interests, awareness, and the culture of society that restricts the girl.

Specialization: In order to answer this question, the ( $\mathrm{T}$ test) was used for the independent samples and the results are in the table (4) below.

Table (4): The results of the (T) test for the two independent samples to identify the role of secondary school teachers in West Bank schools by educating students about the phenomenon of intellectual extremism from the viewpoint of the students themselves according to the specialization variable

\begin{tabular}{|l|l|c|c|c|l|l|}
\hline \multicolumn{2}{|c|}{ Variable } & Frequency & $\begin{array}{c}\text { Arithmetic } \\
\text { mean }\end{array}$ & $\begin{array}{c}\text { Standard } \\
\text { deviation }\end{array}$ & T value & Significance \\
\hline \multirow{3}{*}{ Specialization } & Scientific & 110 & 3.2843 & 0.41878 & $1.129-$ & 0.259 \\
\cline { 2 - 8 } & Humanitarian & 272 & 3.3390 & 0.43159 & & \\
\hline
\end{tabular}


We note from the data in the previous table that there are no statistically significant differences at the level of significance $(\alpha=0.05)$ in the role of secondary school teachers in West Bank schools by educating students about the phenomenon of intellectual extremism from the viewpoint of the students themselves according to the variable of specialization. The value of the significance level reached $(0.25)$ and this value is greater than $(0.05)$. This result means that the responses of the scientific and human specialization are close in judging the role of secondary school teachers in West Bank schools by educating students about the phenomenon of intellectual extremism from the students' viewpoint themselves. That surrounds all parties, which makes them pivotal.

The educational qualification of a parent: In order to answer this question, the ( $T$ test) was used for the independent samples and the results are in the table (5) below.

Table (5): The results of the (T) test for the two independent samples to identify the role of secondary school teachers in West Bank schools by educating students about the phenomenon of intellectual extremism from the viewpoint of the students themselves according to the educational qualification of a parent variable

\begin{tabular}{|c|c|c|c|c|c|c|}
\hline Variable & $\begin{array}{c}\text { Source of } \\
\text { variance }\end{array}$ & $\begin{array}{c}\text { Sum of } \\
\text { squares }\end{array}$ & $\begin{array}{c}\text { Degree of } \\
\text { Freedom }\end{array}$ & $\begin{array}{c}\text { Average } \\
\text { squares }\end{array}$ & P value & Significance \\
\hline \multirow{2}{*}{$\begin{array}{l}\text { The educational } \\
\text { qualification of } \\
\text { a parent }\end{array}$} & Between groups & 0.607 & 2 & 0.303 & 1.661 & 0.191 \\
\cline { 2 - 7 } & Total groups & 69.221 & 379 & 0.183 & & \\
\cline { 2 - 7 } & 69.827 & 381 & & & \\
\hline
\end{tabular}

It is noted from the data in the previous table that there are no statistically significant differences at the level of significance $(\alpha=0.05)$ in the role of secondary school teachers in West Bank schools by educating students about the phenomenon of intellectual extremism from the viewpoint of the students themselves due to the variable of the educational qualification of the parents. The value of the significance level reached (0.19) and this value is greater than (0.05). This result may be attributed to the fact that the largest role of awareness of the phenomenon of intellectual extremism rests with the formal educational institutions in addition to the fact that the social and educational environment for students is unified between different levels, which leads to the unification of conditions between different groups and classes, and this may also be attributed to the parents' preoccupation with securing Conditions for a decent life for their children in the presence of economic crises.

\subsection{Recommendations}

Based on the study results, the researchers recommend the following:

- Setting a strategic plan adopted by the Ministry of Education administration to raise awareness of the phenomenon of intellectual extremism among students and develop a sense of responsibility towards society.

- Develop school curricula and teaching methods so that they focus on the ideological and religious side of society.

- Focusing on activities and teaching methods that support students' intellectual balance.

- Urging researchers to carry out a set of researches in this field.

\section{References}

Al-Agha, Muhammad Hisham (2010): An educational vision out of the crisis of intellectual extremism in the Palestinian society in Gaza governorates. Journal of Al-Azhar University in Gaza, Humanities Series, (2) $12,779-829$.

Al-Huni, Muhammad (2013): The role of the educational system in preventing religious extremism and terrorism. Elaf Magazine, (4562).

Ali, Saeed Ismail (2007): The Origins of Islamic Education, 2nd edition, Dar Al Salam: Cairo, Egypt.

Al-Rawashdeh, Alaa Zuhair (2015): ideological extremism from the perspective of Jordanian youth: Psychological study of appearances and factors. The Arab Journal of Security Studies and Training, 31 (81), 81-121.

Al-Tamimi, Raed and Ramadan, Hussein (2018): The extent of school principals practicing intellectual security to confront the phenomenon of extremism in the intermediate stage from the viewpoint of the principals themselves. International Journal of Research in Educational Sciences, (3) 1,342-386.

Al-Tayyar, Fahd Bin Ali (2007): The role of high school in enhancing security awareness to prevent intellectual extremism. Journal of the College of Education, Al-Azhar University (1) 173, 153-208.

Al-Youssef, Abdullah (2006). Social Forms and Their Role in Resisting Terrorism and Extremism, Unpublished Master Thesis, Naif University for Security Sciences: Riyadh.

Cannatella,B. (2012). The role of ideas of African American students towards violence and extremism 
,Southeastern University, Education,.38(2),190-199.

El-Borai, Wafaa (2002): The University's Role in Facing Intellectual Extremism, University Knowledge House: Alexandria.

Hayek, F. A. (2018). New studies in philosophy, politics, economics, and the history of ideas. University of Chicago Press.

Jose, M. (2008). Globalization, education , and cultural diversity in educational theories and Practices from the majority world. Edited by: Dasen, P. and Akkari, A. SAGE publication, London1(1),5-35.

Kiraly, D. (2014). A social constructivist approach to translator education: Empowerment from theory to practice. Routledge.

Mohamed, Mohamed El-Nasr (2015): Preventive Education for Educational Institutions in the Face of Intellectual Extremism Studies in University Education, Development Center for University Education, Ain Shams University: Egypt.

Qasim, Muhammad Ali Muhammad and Ibrahim, Khalid Ahmed Abdel-Al (2017): The impact of intellectual extremism on the safety of society from the teachers' point of iew. Journal of the College of Education, 34 (1), 122-154.

Simi,P.(2015).trauma as a Precursor to violent Extremism: how non-ideological factors can influence joining an extremist group.https:/www.start.umd.edu/publication/trauma-precursor-violent-extremism 16/2/2019.

UNESCO. 2016. Global Citizenship Education. Topics and Learning Objectives. 